\title{
Impacts of Self-construal Level on Sport Consumer Response to Athlete Scandals: Cross-cultural Approach
}

\author{
Jin Namkung ${ }^{1}$ and Joon Sung Lee* \\ ${ }^{1}$ Yonsei University
}

\section{Article Info \\ Received 2021.09.07. \\ Revised 2021.10.19. \\ Accepted 2021.11.03. \\ Correspondence* \\ Joon Sung Lee \\ leejs929@yonsei.ac.kr}

Key Words

Self-construal,

Individualism,

Collectivism,

Athlete scandal,

Cultural difference

이 논문은 2020학년도 연세대학교 미래 선도연구사업 지원에 의하여 작성된 것임.
PURPOSE This study aimed to test the impact of sport consumers' self-construal levels on their responses toward an athlete scandal by conducting a cross-cultural experimental study. In particular, it focused on sport consumers' subsequent responses toward an athlete scandal, such as the perceived target of responsibility and perceived the main agent for the public apology. METHODS Participants (total=151; KOREA $=75$, USA $=76$ ) were selected for a cross-national comparative study. MANCOVA and Descriptive Statistical Analysis were conducted using the SPSS Windows program version 26.0 to validate the research hypothesis. RESULTS The results indicate that sport consumers' responses to an athlete scandal vary across the countries. Participants from Korea reported perceived responsibility to the athlete, team, and league. Conversely, those from the United States reported perceived responsibility only to the athlete. CONCLUSIONS There are cultural differences in sport consumers' subsequent perceptions of an athlete scandal. The present study's findings are expected to provide stakeholders such as teams and leagues with practical implications to understand better sport consumers' responses to athlete scandals in the globalized sports industry.

\section{서론}

연구의 필요성 및 목적

스포츠 소비자들은 어렵지 않게 운동선수들의 소식을 미디어를 통해 접한다. 2021년 여자배구 선수들의 학폭사건과 프로야구 선수들의 음주파문 등의 사건들이 보여주듯이 운동선수들의 비윤리적 행동과 스캔들은 행위의 시점과 무관하게 각종 매체를 통해 소비자들에게 전달되고 사회의 뜨거운 이슈로 다루어지게 된다. 이러한 현상은 스포츠 시장과 산업의 규모가 확대되고 선수 및 관련 종사자가 늘어남에 따라 더욱 증가하는 추세이다(Brown, 2014; Isaacson, 2012; Yang \& Kang, 2019). 스캔들은 일반적으로 사회규범에 어긋나는 행동으로 인해 특정 분야의 유명인사가 대중으로부터 불명예스러운 관심과 평판을 얻는 것을 말한다(Huh, 2003). 그리고 Hughes와 Shank(2005)는 스포츠 스캔들에 대해 유명선수나 관계자 또는 집단이 경기 안이나 밖에서 도덕적·규범적으로 일탈하는 행위로

(cc) This is an open-access article distributed under the terms of the Creative Commons Attribution Non-Commercial License (http://creativecommons.org/ licenses/by-nc/4.0/), which permits unrestricted non-commercial use, distribution, and reproduction in any medium, provided the original work is properly cited.
대중들에게 널리 인식되는 것이라고 정의했다. 기본적으로 스포츠 스캔들은 경기 내에서 페어플레이(fair play)를 실현하지 못하고 스포츠맨십(sportsmanship)을 훼손했다는 점에서 일반 스캔들과 다르며, 그 양상 또한 다양하다. 스포츠 스캔들을 위기의 유형으로써 다양하게 구분한 국내외 연구들을 살펴보면, 경기장 내와 밖에서 비윤리적이고 불법적인 행위를 통해 발생하는 형태로 구분 짓기도 했다(Kelly et al., 2018). 또는 불가항력에 따른 스포츠 조직의 책임이 낮은 경우와 의도적이거나 심각성이 점차 커지는 중간 및 높은 단계로 구분했다(Brown \& Brown, 2013). 국내의 연구에서도 Bang과 $\mathrm{Kim}(2013)$ 은 경기 관련 위반, 조직 차원 위반, 개인 차원 위반의 3가지 측면으로 유형을 구분하기도 했다. 이처럼 스포츠 내에서 발생하는 다양한 스캔들은 개인에 국한되지 않고 소속구단 및 리그로까지 피해가 확대된다는 점도 특징적이다(Chien et al., 2016). 특히, 대중과 언론에 많은 관심을 받는 특성으로 인해 소속구단은 미디어로부터 상당한 압박을 받기도 한다(Ruihley, et al., 2018). 스포츠 소비자는 스캔들에 실망감과 분노를 표출하고 비난할 수 있는데, 당사자나 관계자들은 이를 회복하기 위해 부단한 노력을 기울여야 하는 상황에 놓이기도 한다.

한편, 스캔들 정보에 노출된 소비자들은 비윤리적 행위에 대하여 각자의 기준에 의거하여 도덕적 판단(moral judgement)을 하게 
된다. Bhattacharjee 등(2013)은 스캔들이 발생했을 때 소비자들은 사전 기대와 현실의 정보가 충돌하는 인지 부조화 (cognitive dissonance)를 경험하게 되고 불편한 심리적 상황을 해소하기 위해 윤리 추론(moral reasoning process) 과정을 거치게 됨을 실증적으로 검증하였다. 이러한 윤리 추론에는 스캔들 대상의 윤리성과 전문성 또는 능력이 분리되는 '윤리성 분리(moral decoupling: MD)'를 언급했다. 이는 운동선수가 스캔들을 일으켰을 때 해당 선수의 비윤리적 행위를 경기능력을 비롯해 그동안 쌓아온 업적과 분리해서 평가하는 방식이다. 한편 Bandura 등(1996)은 특정인의 부정한 행위에 대해 합리화 과정을 거쳐 덜 부정적으로 평가하고 행위자를 지지하는 '윤리성 합리화(moral rationalization: MR)'라는 윤리추론 방식을 제시하였다. 이는 운동선수의 스캔들에 대하여 해당 행동의 위해성을 평가절하하거나 책임의 소재를 다른 인물 혹은 상황으로 돌려 선수의 비행을 정당화하는 방식을 의미한다. 이 방식은 도덕적 판단을 하는 소비자의 윤리 기준을 자발적으로 낮춰야 하는 어려움을 내포하고 있다. 마지막으로 Lee와 Kwak(2016)은 스캔들과 수행 능력을 분리하는 것이 어려운 상황이 존재할 수 있다는 점에 집중하여 대상의 비윤리성과 능력에 대한 평가를 결합(integration)하여 부정적인 반응을 유발하게 시키는 '윤리성 결합(moral coupling: MC)'을 제시했다. 이러한 윤리추론의 접근방식을 채용한 기존 연구에서는 "윤리성 분리와 합리화가 소비자들이 스캔들을 유발한 대상에 대해서 추후에도 긍정적인 평가를 하는 역할을 한다.”고 밝히고 있다(Bhattacharjee, Berman, \& Reed, 2013; Lee \& Kwak, 2016; Lee et al., 2015; Lee et al., 2021). 더불어 이러한 다양한 형태의 윤리 추론방식을 유발시키는 요인으로, 책임의 기인 형태(Lee et al., 2021), 팀 동일시 수준(Lee et al., 2016), 스캔들의 직무 연관성(Lee et al., 2015), 그리고 소비자의 문화적 배경(Lee et al., 2020) 등이 있다고 실증적으로 밝혀졌다.

기존의 연구는 대부분 윤리 추론의 방식에 따른 스캔들의 평가 및 태도를 주요 결과물로써 연구를 진행하였다. 그러나 다양한 판단 기제가 있듯, 소비자도 운동선수의 스캔들에 대해 단순히 대상에 대한 태도나 평가를 넘어서 다양한 판단을 하게 된다. 따라서 본 연구는 스포츠 소비자가 운동선수의 스캔들을 접했을 때 인식하는 책임 및 사과의 주체를 실증적으로 연구하고자 한다. 특히, 본 연구는 이러한 다양한 인식에서 차이를 유발시킬 수 있는 잠재적인 요인으로 스포츠 소비자들의 자기해석의 유형을 사용하고자 한다. Lee 등(2021)은 실제 비교문화연구를 통해 사회 문화적 배경과 부도덕적 행위 유형에 따른 소비자들의 도덕적 추론을 검증하였는데 한국의 소비자들은 '윤리성 결합'을 선택하는 경향이 높았고 미국 소비자들은 '윤리성 분리'를 선호하는 경향이 존재함을 밝혀냈다. 이러한 경향은 소비자의 문화적 배경으로 인한 상이한 자기해석 형태에 따라 유발되었다. 이는 전통적인 자기해석 이론(self-construal theory)로 설명할 수 있다. 자기해석 이론은 개인을 타인과 분리하여 독립적인 존재로 보는 독립적인 자기해석(independent self-construal)과 타인과 조화를 이루고 관계를 맺는 상호의존적인 자기해석(interdependent selfconstrual)으로 인식하는 정서이다(Singelis, 1994). 일반적으로 서양은 독립적인 자기해석을 하며, 동양은 상호의존적인 해석을 한다고 알려져 있다(Hofstede, 1980). 이는 동서양의 분명한 문화적 차이로 인해, 부정적 스캔들에 대한 자기해석수준이 다를 수 있음을 시사한다.

최근 국내 프로스포츠계도 학교폭력 논란으로 홍역을 치른 바
있다. 모 구단에서는 해당 선수뿐만 아니라 감독과 구단 차원에서도 사과를 표명했다. 또한 수년 전 한국프로농구 김선형 선수의 불법도박 사건으로 인해 소속 구단의 코칭스태프를 비롯하여 용병선수들을 포함한 모든 선수단이 시합 전 대관중 사과를 하기도 했다. 이러한 선수의 비윤리적 일탈 행위에 대해서 팀, 구단 혹은 집단수준의 사과가 이루어지는 것은 독립적 자기해석을 기반으로 한 개인주의적 문화가 강한 서양의 문화권에서는 보기 드문 광경들이지만, 역으로 상호보완적이며 집단주의적인 문화를 밑바탕으로 하는 동양권에서는 어렵지 않게 볼 수 있는 현상이다. 문화적 배경에서 기인하는 자기해석수준의 차이로 발생되는 독특한 현상은 스포츠의 맥락에서도 학자들의 관심을 끌어왔다. Markus 등(2006)은 2000년 시드니 올림픽에서 금메달을 획득한 호주.일본 선수 인터뷰를 통해 서양과 동양의 문화적 차이를 분석했다. 미국인 수영선수는 "나에게 집중했고 이 경쟁 자체를 하는 자신이 기뻤다. 승리를 믿어 의심치 않았으며, 오늘은 나의 밤이다.”라는 등의 소감을 밝혔다. 반면, 일본 육상선수는 "세계 최고의 감독과 코치, 그리고 저를 응원하는 모든 사람이 있었다. 나 혼자만으로 할 수 없었다.”라고 말했다. 미국의 문화적 맥락에서는 대상자의 현 경험과 상황을 독립적으로 이해하고 타인과는 상대적으로 분리되어 있으며, 동아시아 맥락에서는 현 상황에 대해 자신의 공간을 만들기보다 전체적인 큰 틀로써 주변으로 확장하고 상호의존적으로 연결하였다(Choi et al., 1999; Dweck, 1988; Plaut \& Markus, 2005). 비스포츠 상황에서도 이를 설명하는 사례가 있다. 과거 2007년 큰 충격을 주었던 미국 버지니아 공대에서 발생한 한국계 대학생 조승희의 총기 난사 사건이다. 해당 사건이 최악의 학교 총기 사건으로 불리며 한국은 집단적 죄의식에 빠졌고, 국내의 언론은 견고한 한미관계를 지속적으로 확인시키며 대중을 안심시키려 했다(Kang, 2007). 특히 국내 언론은 사건의 본질과 다르게 집단주의적이고 인종주의적이면서 민족주의적인 관점으로 앞다투며 보도를 했다(Kim, 2007). 반면 미국 언론에서는 사건을 일으킨 행위 주체에 대해 독립적인 존재로 보며 중립적이고 조심스럽게 접근했다(Lee et al., 2008). 이렇듯 동일한 사건에 대하여서도 국가별로 상이한 반응을 보이는 것은 동서양의 문화적 차이에 의해 형성된 자기해석수준에 의한 것으로 볼 수 있다. 자신이 속한 문화에 따라 달라지는 자기해석수준과 문화적 차이는 특정 행동에 영향을 미친다(Hofstede \& Bond, 1988). 이때 자신을 타인과 독립된 존재로 인식하거나 상호의존적인 존재로 인식하는 심리적 차이가 존재하며 자기해석은 자신이 속한 문화적 맥락에 따라 다르게 발생하는 것이다(Markus \& Kitayama, 1991).

타 분야의 국외 연구에서는 독립적 자기해석을 하는 사람들에게는 개인 지향적 가치를 강조하는 메시지를 제시하고, 상호의존적 자기해석을 하는 집단에게는 집단지향적 메시지가 기업 태도에 호의적이라고 하였다(Zhang \& Gelb, 1996). 그리고 상호의존적인 집단은 다양성을 추구하며 폭넓고 복잡한 환경을 선호하는 반면, 독립적인 성향의 집단은 단순한 절차와 환경을 추구한다고 주장하기도 했다(Nisbett \& Miyamoto, 2005). 국내의 연구에서는 같은 광고를 제시했을 때 상호의존적인 사람들은 대상뿐만 아니라 그 주위를 둘러싼 맥락정보를 같이 고려하며, 독립적 성향인 사람들은 대상 자체에만 주목한다고 밝혔다(An \& Lee, 2011). 이처럼 다양한 형태의 자기해석수준에 따른 연구가 활발히 이어지고, 스포츠 산업 또한 세계화의 물결에 편승하여 지속적으로 성장하고 있지만, 문화적 차이로 인한 스포츠 소비자의 자기해석수준에 관한 연구는 
상대적으로 미비하다. 특히, 스포츠 스캔들과 관련하여 상호의존적 문화를 가진 한국과 독립적 문화를 가진 서양을 비교하면, 소비자의 차이를 이해하는 데 도움이 될 것이다. 따라서 본 연구의 목적은 스캔들에 대한 소비자의 반응을 문화적 차이로 인한 자기해석수준에 따라 비교 분석하는 데 있다. 구체적으로는 상호의존적인 특성이 있는 동양문화권의 한국 스포츠 소비자와 독립적인 특성을 보이는 서양권의 미국 스포츠 소비자가 인지하는 스캔들에 대한 책임의 범위 및 사과의 주체를 비교 검증하는 것이다. 선수의 스캔들이 발생했을 때 소비자들은 그들의 자기해석수준에 따라 상이한 윤리 추론 과정을 거칠 것(Lee et al., 2021)이며, 이로 인해 책임의 범위와 사과의 주체를 다르게 인식할 것으로 예상된다.

\section{연구 가설}

1. 운동선수의 스캔들에 대해 스포츠 소비자들이 인식하는 책임 수준의 차이

인간의 자아는 태어날 때부터 타고난 것이 아닌 사회적 상호작용을 통해 학습된다(Triandis, 1989). 즉, 다른 문화적 배경은 서로 다르게 학습되어 자기해석수준이 달라질 수 있다. 이러한 과정을 통해 서양권의 사람들은 어떤 사건이나 행동에 대해 추상적인 수준으로 이해하며 독립적으로 자기해석을 한다. 반면, 상호의존적인 동양권 사람들은 구체적인 수준으로 특정 현상이나 상황을 이해한다(Spassova \& Lee, 2013). 특히, 상호의존적인 자기해석은 한국을 포함하여 유교적 문화권을 띄는 동양에서 집단주의 문화를 보인다고 주장했다(Lee et al., 2011; Markus \& Kitayama, 1991). 그리고 서양인들은 대상의 근원에 초점을 두어 주변 환경을 분리하는 방식(disjoint way)을 사용하며, 동양인들은 대상과 주변 환경을 함께 바라보는 결합된 방식(conjoint way)을 사용한다고 한다(Markus et al., 2006). Goodman과 Malkoc(2012)는 사건과 행동을 추상적인 수준으로 이해하는 독립적인 집단은 제품도 집합을 이루는 형태에 대한 선호도가 낮다고 했다. 반면, 상호의존적인 사고는 큰 집합 형태에 대한 선호도가 증가한다고 한다. 본 연구에서는 선수의 스캔들이 발생했을 때 양쪽 국가(한·미)의 스포츠 소비자들은 책임의 주체가 다를 것임을 가정하였다. 따라서 문화에 따른 자기해석수준에 관련한 선행 연구들을 바탕으로 다음과 같은 가설을 설정하였다.

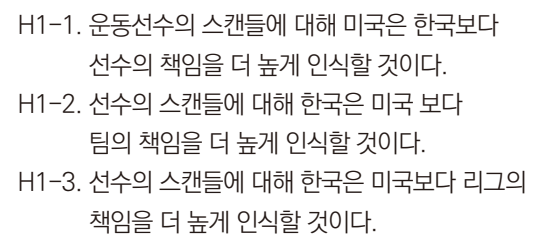

2. 운동선수의 스캔들에 대해 스포츠 소비자들이 인식하는 사과 주체의 차이

개인적인 문화를 지닌 서구권에서는 독립적인 자기해석을 하고 타인과의 독립을 통해 자신을 분리하며 직접적인 소통을 선호하면서 독특성을 중시한다(Hardin et al., 2004). 이에 반해 집단적인 문화를 지닌 동양권에서는 타인과의 조화를 중요시하며 사회적인 관계를 추구한다고 주장한다(Cousins, 1989; Triandis, 1989). 즉, 서양인들은 집단으로부터 감정적으로 독립된 상태를 띄는 경우가 많아 개인주의 성향이 강하다고 알려진 반면, 동양인들은 구성원들과
조화를 통해 관계를 맺는 집단주의 성향이 강하다(Hofstede, 1980). 이러한 특성을 통해 개인주의적 문화를 지닌 서양인들은 특정 사건이 발생했을 때 대상의 근원과 행위의 주체에 집중하고 판단하며 동양인들은 대상과 주변 환경을 함께 바라보는 차이가 존재한다(Kitayama, et al., 2003). Lee 등(2020)의 연구에서는 선수의 스캔들(경기 내·외적)이 발생했을 때 동·서양에서 인식하는 도덕적 추론의 차이가 있음을 밝혔다. 또한, 서양인은 대상에 초점을 두고 내적 속성에 근거하여 판단하지만, 동양인은 집단주의적인 사고로 대상을 둘러싼 주변에 기울이고 대상과 분야의 관계를 함께 고려하여 판단하게 된다고 한다(Nisbett \& Masuda, 2003). 이처럼 문화적 차이로 인해 선수의 스캔들이 발생하면 팬들이 인식하는 사과의 주체가 달라질 수 있을 것이다. 이에 본 연구는 이론적인 바탕과 선행 연구를 토대로 자기해석수준에 따라 문화적 차이가 있음을 확인하며, 다음과 같은 가설을 설정하였다.

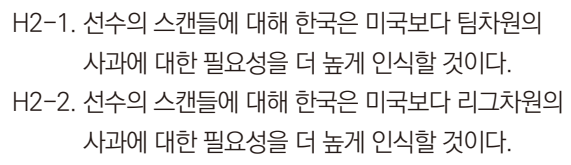

\section{연구방법}

\section{연구대상}

본 연구를 진행하기 위해 자기해석수준에 대해 상호의존적 성향과 독 립적 성향을 주요 독립변인으로 하여 실험을 설계했다. 상호의존적인 성향을 보이는 동양권에서는 한국을 선정하였고 독립적 성향을 띄 는 서양권에서는 미국을 채택하여 국가별 비교 연구(a cross-national comparative study)를 진행했다. 본 연구의 특성상 한국인과 미국인 을 모집단으로 설정하였으며 편의표본추출법(convenient sampling

Table 1. Characteristic subjects

\begin{tabular}{|c|c|c|c|}
\hline Variables & Content & Number & Frequency $(\%)$ \\
\hline \multirow{2}{*}{ Country } & Korea & 75 & 49.7 \\
\hline & USA & 76 & 50.3 \\
\hline \multirow{2}{*}{ Gender } & Male & 76 & 50.3 \\
\hline & Female & 75 & 49.7 \\
\hline \multirow{3}{*}{ Ages } & Twenties & 68 & 45.0 \\
\hline & Thirties & 58 & 38.4 \\
\hline & Forties & 20 & 13.2 \\
\hline \multirow{6}{*}{ Race } & American Indian /Alaskan Native & 1 & 0.7 \\
\hline & Asian & 78 & 51.7 \\
\hline & African-American & 7 & 4.6 \\
\hline & Hispanic & 7 & 4.6 \\
\hline & Caucasian & 57 & 37.7 \\
\hline & etc. & 1 & 0.7 \\
\hline & Total & 151 & 100 \\
\hline
\end{tabular}


method)에 따라 표집 되었다. 웹 기반 설문 제작 플랫폼인 퀄트릭스 (Qualtrics)를 사용하여 설문을 제작하였으며, 연구 대상자는 G*Power 3.1 Program을 이용하여 차이 분석에 필요한 유의 수준 .5, 효과크기 .25 , 검정력 .8 로 계산하여 최소 128 명의 연구 대상자가 산출되었으며, 본 연구의 참여자는 양국의 유료 설문 패널 서비스를 통하여 최종적으 로 총 151 명을 모집하였다. 설문 시간은 약 10 분 정도 소요되었고 연구 참여자들의 인구통계학적 특성은 한국인과 미국인 비율(5:5), 남녀 비율 (5:5), 평균 연령(31세), 인종 비율(Caucasian 37\%) 등이며, 구체적인 특성 은 〈Table 1〉과 같다.

\section{측정도구}

무선 배치된 실험 참여자들의 반응을 측정하기에 앞서 참여자들에게 스캔들 상황을 〈Table 2 〉와 같이 제시하였다. 마음속에 뛰어난 기량을 가진 자국의 유명한 축구 선수를 떠올린 후 이에 대한 참여자의 반응을 측정하였다. 특히, 특정 리그에서 활동 중인 선수의 이름, 국적을 특정하였을 때 기존에 형성되어 있는 해당 선수와 국가, 그리고 리그에 대한 인식으로 인해 발생될 수 있는 교란효과(confounding effect)를 방지하기 위해 시나리오는 자국 리그에서 활동 중인 불특정 선수를 떠올리도록 요구하였다. 또한, 본 연구의 시나리오에 사용된

Table 2. Scenario related to sport scandal

\begin{tabular}{ll}
\hline & \multicolumn{1}{c}{ Scenario } \\
\hline In your mind, recall a controversial situation in which a \\
soccer player in a domestic league has committed an un- \\
gthlete's \\
scandlemanly act during a match. The athlete was found \\
to have deliberately stepped on the opponent's key play- \\
er's ankle during a recent match, causing serious injuries \\
for more than three weeks of preposition.
\end{tabular}

운동 종목(soccer)과 스캔들의 종류(a deliberate foul during a match)는 총 129 명(KOREA=68; USA=61)의 참여자를 양국의 유료 패널 서비스를 통해 모집하여 진행한 사전검사(pilot test)를 통하여 선정하였다. 사전검사 참여자들은 자유롭게 운동선수를 통해 연상될 수 있는 두 가지의 일반적인 비윤리적 행동에 대하여 떠올려 답하였고, 한국 참여자의 $52 \%$, 미국 참여자의 $49 \%$ 가 떠올린 시합 중 고의적인 파울로 상대 선수에게 부상을 입히는 행위가 가장 높은 빈도를 보여 이를 선정하였으며, 차상위의 비윤리적 행동으로는 한국은 경기장 밖에서의 폭력행위(16\%), 음주운전(13\%), 승부조작(12\%), 기타(7\%), 그리고 미국은 살인(19\%), 도핑(14\%), 약물복용(14\%), 기타(4\%)로 확인되었다. 또한, 시나리오에 사용될 종목은 참여자들이 가장 쉽게 연상할 수 있는 상위 4 개의 운동 종목 중 한국(축구(53회), 야구(47회), 피겨스케이팅(25회), 수영(21회))과 미국(미식축구(46회), 농구(44회), 축구(23회), 야구(19회))에서 공통적으로 발견된 축구와 야구 중 응답빈도가 더욱 높은 축구를 선정하였다. 특히, 본 연구에 사용할 수 있는 측정 도구들이 기존의 문헌에 존재하지 않는 상황을 고려하여 설문을 위한 문항들은 연구의 목적에 맞게 연구자들이 자체개발한 단일문항으로 사용하였다. 연구에서 사용된 책임과 사과 변수는 연구자들이 학계 관련 전문가들과 심도 깊은 논의 과정을 거쳐 확정된 단일문항으로 측정되었다. 이러한 단일문항의 사용은 구성개념을 설명하는 문항이 자기보고식 사실을 측정할 때 일반적으로 사용될 수 있으며(Wanous et. al., 1997), 응답시간을 단축하여 지루함을 없애고 직관적인 응답을 유도하여 더욱 정확한 자료수집을 유도할 수 있는 장점이 있다(Gardner et. al., 1998). 종속변수인 인지된 책임(선수 책임, 팀 책임, 리그 책임)은 각각의 단일문항으로 구성된 총 3 문항으로 해당 대상과 비난의 범위도 함께 제시했다. 문항의 예시는 "시나리오 속의 사건은 00 의 책임이며, 나는 00 (을)를 비난할 것이다.”로 작성되었으며 제시어는 '해당 축구 선수, 축구 선수의 소속팀, 선수가 활동 중인 리그’이다. 사과의 문항도 단일문항 형태이며, 총 2문항(팀, 리그)으로 구성되었다. 문항의 예시는 "소속팀은 해당 선수의 잘못된 행동에 대해

Table 3. MANCOVA of responsibility differences in cultural areas

\begin{tabular}{|c|c|c|c|c|c|c|c|c|}
\hline & Variables & Sum Sq & $D f$ & Mean Sq & $F$ & $p$ & $\mathrm{Eta}^{2}$ & $\begin{array}{l}\text { Wilks' } \\
\text { Lambda }\end{array}$ \\
\hline \multirow{4}{*}{$\begin{array}{l}\text { Athlete } \\
\text { responsibility }\end{array}$} & Soccer involvement & 0.509 & 1 & 0.509 & 0.584 & .446 & .004 & \multirow{12}{*}{.750} \\
\hline & Athlete identification & 4.450 & 1 & 4.450 & 5.100 & .025 & .034 & \\
\hline & Country (KOREA·USA) & 26.386 & 1 & 26.386 & $30.240 * * *$ & .000 & .171 & \\
\hline & Error & 128.266 & 147 & 0.873 & & & & \\
\hline \multirow{4}{*}{$\begin{array}{c}\text { Team } \\
\text { responsibility }\end{array}$} & Soccer involvement & 2.521 & 1 & 2.521 & 1.403 & .238 & .009 & \\
\hline & Athlete identification & 1.400 & 1 & 1.400 & 0.779 & .379 & .005 & \\
\hline & Country (KOREA·USA) & 34.034 & 1 & 34.034 & $18.934 * * *$ & .000 & .114 & \\
\hline & Error & 264.239 & 147 & 1.798 & & & & \\
\hline \multirow{4}{*}{$\begin{array}{c}\text { League } \\
\text { responsibility }\end{array}$} & Soccer involvement & 0.495 & 1 & 0.495 & 0.255 & .614 & .002 & \\
\hline & Athlete identification & 8.310 & 1 & 8.310 & 4.278 & .040 & .040 & \\
\hline & Country (KOREA·USA) & 25.718 & 1 & 25.718 & $13.239 * * *$ & .000 & .083 & \\
\hline & Error & 285.557 & 147 & 1.943 & & & & \\
\hline
\end{tabular}

$* p<.05, * * p<.01, * * * p<.001$ 
Table 4. MANCOVA of apology differences in cultural areas

\begin{tabular}{|c|c|c|c|c|c|c|c|c|}
\hline & Variables & Sum Sq & $D f$ & Mean Sq & $F$ & $p$ & $\mathrm{Eta}^{2}$ & Wilks' Lambda \\
\hline \multirow{4}{*}{$\begin{array}{c}\text { Team } \\
\text { apology }\end{array}$} & Soccer involvement & 18.322 & 1 & 18.322 & 6.826 & .010 & .044 & \multirow{8}{*}{.884} \\
\hline & Athlete identification & 0.067 & 1 & 0.067 & 0.025 & .875 & .000 & \\
\hline & Country (KOREA·USA) & 37.738 & 1 & 37.738 & $14.059 * * *$ & .000 & .087 & \\
\hline & Error & 394.591 & 147 & 2.684 & & & & \\
\hline \multirow{4}{*}{$\begin{array}{l}\text { League } \\
\text { apology }\end{array}$} & Soccer involvement & 14.269 & 1 & 14.269 & 4.948 & .028 & .033 & \\
\hline & Athlete identification & 0.416 & 1 & 0.416 & 0.144 & .705 & .001 & \\
\hline & Country (KOREA·USA) & 54.166 & 1 & 54.166 & $18.784 * * *$ & .000 & .113 & \\
\hline & Error & 423.897 & 147 & 2.884 & & & & \\
\hline
\end{tabular}

${ }^{*} p<.05, * * p<.01, * * * p<.001$

공개적으로 사과해야 한다.", "소속리그는 해당 선수의 잘못된 행동에 대해 공개적으로 사과해야 한다."로 구성했다. 문항은 리커트 7점 척도를 사용 하였으며 공변인으로 축구에 대한 종목 관여도(Zaichkowsky, 1985, 4 questions; $\alpha=.96[$ [KOREA]/.98[USA])와 선수 동일시(Trail \& James, 2001; 3 questions; $\alpha=.92$ [KOREA]/.98[USA])를 투입하였다. 선행연구에서는 높은 관여도 수준을 지닌 그룹은 낮은 수준의 그룹보다 운동선수의 비행을 업적과 분리하는 '윤리성 분리'가 높게 이뤄졌을 뿐만 아니라 스캔들을 정당화하는 '윤리성 합리화'를 추구하며 결국, 브랜드 태도에 긍정적인 평가를 한다고 했다(Lee \& Kwak, 2016). 또한, 스포츠팬으로서 높은 수준의 동일시를 인지하고 있으면 팀과 관련된 안 좋은 정보를 해당 팀 또는 선수와 분리 하고 이를 받아들이지 않는 성향이 있다고 한다(Iyer et al., 2012; Chien et al., 2016). 따라서 본 연구는 이를 바탕으로 관여도와 동일시가 독립변수 외의 변수로써 종속변수에 영향을 미칠 수 없도록 통제하였다. 또한 시나리오에 나타난 운동선수의 비윤리적 행동의 종류를 묻는 주의 점검(attention check) 문항을 사용하였으며, 모든 연구 참여자들이 올바른 답을 선택하였다.

\section{자료처리 방법}

본 연구의 시나리오는 사전검사(pilot test)를 통해 종목과 스캔들을 점검하고 선정하였으며, 연구 대상자들은 한국인과 미국인으로 온라인 설문인 Qualtrics에서 진행되었다. 설문이 종료된 후 설문 웹 사이트에서 원자료를 다운로드를 한 후 IBM SPSS Ver. 26 프로그램을 통해 코딩하였다. 이후 응답자의 일반적 특성을 위한 빈도분석을 진행하였으며, 다변량공분산분석(Multivariate Analysis of Covariance: MANCOVA)과 기술통계 분석(Descriptive Statistical Analysis)을 수행하였다. 스포츠 스캔들에 대한 소비자들의 반응을 국가간의 비교 검증을 통해 차이를 분석하였으며, 본 연구에서 진행한 실증분석은 유의수준 $\mathrm{a}=.05$ 에서 검증하였다.

\section{연구결과}

\section{연구 검증}

운동선수의 스캔들에 대한 책임의 범위와 사과 주체의 차이를 검증하기
Table 5. Descriptive statistics of responsibility and apology

\begin{tabular}{|c|c|c|c|}
\hline & & \multicolumn{2}{|c|}{ Country } \\
\hline & & Korea $(n=75)$ & USA $(n=76)$ \\
\hline \multirow{2}{*}{$\begin{array}{c}\text { Athlete } \\
\text { responsibility }\end{array}$} & Mean & 5.73 & 6.66 \\
\hline & $(S D)$ & $(1.07)$ & $(0.80)$ \\
\hline \multirow{2}{*}{$\begin{array}{c}\text { Team } \\
\text { responsibility }\end{array}$} & Mean & 3.43 & 2.41 \\
\hline & $(S D)$ & $(1.32)$ & $(1.39)$ \\
\hline \multirow{2}{*}{$\begin{array}{c}\text { League } \\
\text { responsibility }\end{array}$} & Mean & 3.09 & 2.14 \\
\hline & $(S D)$ & $(2.14)$ & $(1.42)$ \\
\hline \multirow{2}{*}{$\begin{array}{c}\text { Team } \\
\text { apology }\end{array}$} & Mean & 5.44 & 4.41 \\
\hline & $(S D)$ & $(1.11)$ & $(2.11)$ \\
\hline \multirow{2}{*}{$\begin{array}{l}\text { League } \\
\text { apology }\end{array}$} & Mean & 5.05 & 3.79 \\
\hline & $(S D)$ & $(1.25)$ & $(2.13)$ \\
\hline
\end{tabular}

위해 공분산 분석을 시행하였다. 선수의 부도덕한 스캔들이 발생했을 시 책임의 범위(athlete, team, league)와 사과의 주체(team, league)를 종속 변인으로, 축구에 대한 관여도와 선수 동일시를 공변인으로 투입하여 MANCOVA를 시행하였다. 책임과 사과의 독립변수의 수준들간 유의미한 차이를 검증하기 위해 Wilks' Lambda 값을 사용(Brace, Kemp \& Snelgar, 2003)하였으며, 유의수준은 .05로 설정하였다. 또한, $F(3,145)=16.109, p<.001$, Wilks' $\Lambda=.750$, partial $\eta^{2}=.250$ 으로 국가에 따라 책임의 범위에서 차이가 있는 것으로 나타났다. 양 국가에서 인식하는 선수 책임에 대한 차이 및 가설 1-1의 결과는 〈Table 3〉, 〈Table 5〉와 같다. 가설을 검증한 결과, 운동선수의 스캔들이 발생했을 때 선수의 책임에 대한 소비자들의 반응은 그들의 축구 관여도 및 선수 동일시의 영향을 통제한 상황에서 문화권에 따라 유의한 차이를 보였다( $F=30.240, p<.001)$. 구체적으로는 미국( $M=6.66$, $S D=0.80)$ 이 한국 $(M=5.73, S D=1.07)$ 보다 선수의 책임이 높게 나타나 가설 1-1은 채택되었다. 양쪽 국가에서 인식하는 팀 책임의 차이 및 세부적인 결과도〈Table 3〉과 〈Table 5〉와 같다. 가설 1-2의 결과에서는 축구 관여도 및 선수 동일시의 영향을 통제한 상황에서 스캔들에 대한 팀의 책임에 대해 소비자들의 반응은 문화권에 따라 유의한 차이가 있었다( $F=18.934, p<.001)$. 구체적으로는 한국 $(M=3.43$, 
$S D=1.32)$ 이 미국 $(M=2.41, S D=1.39)$ 보다 팀의 책임을 더욱 높게 인지하였다. 따라서 가설 1-2는 채택되었다. 소속 리그 책임의 차이 및 세부적인 결과 역시〈Table 3〉과〈Table 5〉와 같다. 가설 1-3의 결과에서도 스포츠 소비자들의 축구 관여도 및 선수 동일시의 영향을 통제한 상황에서 소비자들이 느끼는 리그의 책임은 문화권에 따라 유의한 차이가 나타났다 $(F=13.239, p<.001)$. 리그 책임 역시 한국 $(M=3.09, S D=1.45)$ 이 미국 $(M=2.14, S D=1.42)$ 보다 높게 인식하는 것으로 나타나 가설 1-3은 채택되었다. 양쪽 국가에서 인식하는 사과의 주체는 $F(2,146)=9.582, p<.001$, Wilks' $\Lambda=.884$, partial $\eta^{2}=.116$ 으로 국가에 따른 사과의 범위에서 차이가 있는 것으로 나타났다. 이에 대한 차이검증 및 가설 2-1의 결과는 〈table 4〉, 〈table $5>$ 와 같다. 가설을 검증한 결과, 운동선수의 스캔들이 발생했을 때 축구 관여도 및 선수 동일시의 영향을 통제한 후 스포츠 소비자들이 느끼는 소속 팀 사과는 국가에 따라 유의한 차이를 보였다 $(F=14.059$, $p$ <.001). 구체적으로는 한국 $(M=5.44, S D=1.11)$ 이 미국 $(M=4.41$, $S D=2.11$ )보다 높게 나타나서 가설 2-1은 채택되었다. 양쪽 국가에서 인식하는 소속 리그 사과의 차이 및 세부적인 결과도〈table 4〉와 〈table 5〉와 같다. 가설을 검증한 결과, 축구 관여도 및 선수 동일시의 영향을 통제한 상황에서 소비자들의 인지하는 소속 리그의 사과는 가설 1-2와 마찬가지로 양쪽 국가에서 유의한 수준 차이를 보였다 $(F=18.784, p<.001)$. 구체적인 차이로는 한국 $(M=5.05, S D=1.25)$ 이 미국 $(M=3.79, S D=2.13)$ 보다 높게 인식되었다. 따라서 가설 2-1은 채택되었다.

\section{논의}

본 연구는 선수의 스캔들로 인해 스포츠 소비자들이 느끼는 책임의 범위와 사과의 주체가 소비자들의 자기해석수준에 따라 달라질 것이라는 가정하에 동양권 문화인 한국과 서양권 문화인 미국을 대상으로 연구를 진행했다. 타인으로부터 독립과 분리를 추구하는 독립적 자기해석의 성향은 서양 문화권에서 주로 나타나며 특히 미국은 운동선수의 스캔들에 대해 선수와 팀 또는 구단과 분리를 하여 해석하는 것으로 드러났다. 즉, 미국인은 스캔들을 일으킨 해당 선수에 초점을 맞춘다. 반면, 한국에서는 스캔들이 발생했을 경우 선수와 팀 그리고 리그 차원까지 고려하는 것으로 나타났다. 그리고 국가에 따라 스캔들의 책임과 사과는 차이가 나는 것으로 드러났다. 이러한 결과는 스포츠 소비자의 문화적 배경에 기인한 자기해석수준의 차이가 운동선수의 스캔들을 해석하고 반응하는 데에 상이한 영향을 끼친다는 것을 입증한다고 할 수 있다. 본 연구에서 운동선수의 스캔들이 발생했을 때 문화권에 따라 책임의 대상과 사과의 범위에 대한 차이 구분을 위해 설정한 연구 가설 및 결과 분석의 구체적인 논의는 다음과 같다.

\section{1. 문화권에 따라 선수의 스캔들에 대해 스포츠 소비자들이 인식하는 책임의 범위}

먼저, 스포츠 스캔들에 있어 팬들이 인식하는 책임의 주체는 문화권에 따라 차이가 있는 것으로 드러났다. 스캔들이 발생했을 때 동양 문화권 소비자들은 선수의 책임을 상대적으로 낮게 인식하는 반면, 서양 소비자들은 선수 차원의 책임을 상대적으로 높게 인식할 것이라는 가설 1-1은 지지 되었다. 전통적으로 독립적인
자기해석수준을 가진 미국과 상호의존적인 문화를 추구하는 한국은 스캔들의 책임에 대해 인식하는 범위가 달랐다. 본 연구는 운동선수의 스캔들에 대한 소비자들의 반응 차이를 문화적 차이에 근거하여 실증적으로 규명하였으며, 미국 소비자들은 한국 소비자들보다 선수가 저지른 스캔들에 대해 본인 스스로 책임을 져야 한다는 인식이 강함을 확인하였다. 상대적으로 독립적인 성향이 강한 미국 소비자들을 운동선수에 의해 발생한 스캔들을 해당 선수의 잘못이라고 주로 판단하였다. 이러한 결과는 서양이 동양과 달리 개인을 다른 이해관계자와 구별되는 독립적인 존재로 보며 독립성과 자기 의존(self-reliance)의 가치를 중요시하기 때문이다(Lim, 2019). 게다가 서양권인 미국은 개인주의적 문화가 발달했고 독립성에 높은 가치를 두기 때문에 자신 또는 타인의 근원에 초점을 맞추는 것이라고 볼 수 있다(Markus \& Kitayama, 1991). 이와 달리 선수의 스캔들에 대해 소속팀의 책임 소재를 묻는 부분에서 한국이 미국보다 높게 인식했다. 따라서 가설 1-2은 채택되었다. Wang과 Mowen(1997)에 따르면 동양 문화권의 사람들은 상호의존적 자기해석이 강하게 나타나기 때문에 타인 또는 소속된 조직 내에서 조화를 이루고 유기적인 연계(connectedness)와 관계(relationship)를 강조한다고 했다. 즉, 타인과 조화를 이루며 자신을 집단의 일부로 생각하는 동양권에서는 '우리'라는 관점으로 사고하는 경향이 있는 것이다(Park \& Ryu, 2012). 따라서 국내의 스포츠 소비자들은 스캔들에 대해 해당 선수뿐만 아니라 주변 환경인 소속팀까지 고려한다고 볼 수 있다. 반면 서양 문화권인 미국의 소비자들은 한국 소비자들보다 팀의 책임을 상대적으로 낮게 인식하였다. 이에 Waterman(1984)은 개인주의 특성 중 책임소재와 관련되어 개인의 행복과 불행은 자신의 책임이며, 원칙적이고 도덕적 이성을 갖추고 판단해야 한다고 언급하였다. 즉, 선수로 인해 유발된 부정적인 스캔들의 주체인 선수 자신의 책임이라는 것이다.

한편, 스캔들에 대해 리그 차원의 책임을 한국 소비자들이 상대적으로 더욱 높게 인식하였다. 이렇듯 한국이 미국보다 리그 차원의 책임소재도 높게 인식하는 것으로 나타나 가설 1-3은 채택되었다. 상호의존적인 성향을 지닌 문화권에서는 특정 상황에서 발생하는 모든 요소가 서로 연결되어 있다고 판단하며, 결국 대상을 전체 요소로부터 분리하여 이해하는 것은 어렵다고 판단하는 것이다(Nisbett et al., 2001). 이는 선수가 발생시킨 스캔들의 책임소재에 있어 자기해석수준에 따라 책임의 정도와 범위가 달라지는 것으로 이해할 수 있다. 한국 소비자들은 스캔들을 발생시킨 선수에게 일차적인 책임을 묻는 동시에 소속된 팀도 관리 소홀과 같은 일정 부분에 대한 책임이 있다고 답하였다. 본 연구에 사용된 선수 관련 스캔들은 자신이 떠올린 선수가 시합 중 고의로 상대 팀 선수의 발목을 밟아 심각한 부상을 유발한 비신사적인 행위로 설정이다. 이에 미국은 한국보다 팀과 리그의 책임을 낮게 인식하였는데, 이는 Bhattacharjee 등(2013)이 제시한 것처럼 미국 스포츠 팬들이 스캔들과 선수의 능력을 별도의 영역으로 평가한 윤리성 분리(moral decoupling: MD)를 통해 윤리 추론을 한 것으로 보인다. 이에 반해 한국에서는 원인을 제공한 선수도 잘못이 있고 소속집단도 그 책임이 있다고 평가했다. 이러한 배경에는 동양 문화권 사람들이 특정 문제나 사회적인 상황을 소속집단과 같은 선상에 두고 판단한다는 사실이 놓여있다(Kanagawa et al., 2001). 이처럼 문화권에 따라 스캔들을 다르게 인식하므로 대응은 달라질 수 있다. 가령 미국의 경우, 스캔들 당사자인 선수는 책임감이 높은 만큼 
이미지 하락이 크게 우려되고 대중에게 좋지 않은 평판을 받을 수 있다. 이에 스캔들을 일으킨 선수는 책임을 부인하거나 회피하기보단 사죄(mortification)를 하는 것이 선수의 이미지를 회복하는데 효과적 일 것이다(Brown et al., 2012). 반면 국내에서는 스캔들을 분리하여 해당 조직의 책임성을 제거하는 희생양(scapegoating)을 만드는 전략은 바람직하지 않다(Coombs, 2014). 대중들은 해당 사건을 일으킨 선수를 비롯하여 이 선수가 소속된 해당 조직(팀, 리그) 또한 상대적으로 책임이 있다고 믿는다는 본 연구의 결과가 이를 설명할 수 있다. 이는 선수의 비윤리적 행위는 선수 개인의 문제가 아닌 선수가 속한 상위 조직의 문제이기도 하다고 믿는 동양문화권의 소비자들이 비행의 주체인 선수와의 분리를 통해 조직을 향한 비난의 화살을 피하려는 조직의 전략에 오히려 더욱 강한 비난을 가할 수 있기 때문이다. 즉, 국내의 스포츠 현장에서 일어나는 선수의 스캔들에 대해서 국내의 스포츠 소비자들은 선수 개인의 책임을 뛰어넘어 팀과 리그 차원에서도 선수관리와 예방이라는 상위조직의 역할과 기능을 다하지 못한 책임이 있다고 인지하는 경향이 존재하기 때문에 조직 차원의 진정성 있는 사과와 실현 가능한 개선 노력을 통해 이러한 위기 상황에 대처해야 할 것으로 판단된다.

\section{2. 문화권에 따라 스포츠 소비자들이 인식하는 선수 스캔들의 사과 주체}

스캔들은 '비난받을 만한 사건(blameworthy event)' 이란 용어로 사용되기도 한다(Louie, Kulik, \& Jacobson, 2001). 운동선수의 스캔들이 발생했을 때도 스포츠 소비자들은 해당 사건에 대해 비난하고 사과를 요구할 수 있다. 본 연구에서는 문화권에 따라 스포츠 소비자들이 인식하는 사과의 주체도 차이가 존재했다. 먼저 선수의 스캔들에 대해 한국은 미국보다 소속팀의 사과를 높게 인식할 것이라는 가설 2-1은 유의한 차이가 있는 것으로 나타나 가설은 채택되었다. 실제로 선수의 스캔들이 발생하면 한국은 해당 선수의 비행에 대하여 미국보다 높은 수준으로 소속팀에서 사과해야 한다고 인식하고 있었다. 이는 동양권의 문화가 개인의 생각이나 감정 또는 행동들을 집합적인 개념으로 여기며, 둘러싸인 주변 환경과 위치를 의식하고 사고하는 경향이 있다(Kitayama et al., 2003; Singelis, 1994)는 선행연구의 결과가 뒷받침 한다고 볼 수 있다. 즉, 한국인은 미국인 보다 맥락적 프레임을 통해 사고하기 때문에 스캔들이 발생했을 때 선수가 속한 팀과 리그 차원에서도 책임을 지고 사과해야 한다고 인식하는 것이다. 운동선수의 스캔들은 그 특성에 따라 자신이 소속되어 있는 팀이나 리그를 비롯한 스포츠 전체에 대한 비난으로 발전될 가능성을 언급했다(Park \& Park, 2011). 이에 대해 동양 문화권의 스포츠 소비자들은 선수의 스캔들이 발생하면 소속팀 차원의 사과를 더욱 기대한다고 해석할 수 있다. 소속팀은 선수의 스캔들이 일어났을 때 효과적인 위기극복전략으로 공동의 책임을 인정하는 사과를 표하는 것이 팬들의 마음을 진정시킬 방안일 것이다.

한편, 선수의 스캔들에 대해 리그 차원의 사과도 한국이 높게 인식할 것이라는 가설 2-2도 유의한 차이가 나타나 가설이 채택되었다. 운동선수들의 부정적 스캔들은 선수가 속한 집단의 관리능력에 대해 팬들과 언론으로부터 비판에 직면하고 대외이미지가 하락하는 경우가 발생하기도 한다(Osborne et al., 2016). 리그 또한, 소속팀 보다 상위 조직으로서 선수와 연계되어 있음을 볼 때 선수의 스캔들로부터 무관하다고 볼 수 없을 것이다. 실제 한국은 스캔들에
대해 리그 차원의 사과에서 미국보다 월등히 높게 인식하고 있었다. Shen 등(2011)은 상호의존적인 자기해석이 높은 성향은 독립적인 성향보다 규칙, 의무, 규범 등을 중요시하게 생각한다고 했다. 더욱이 동양권에서 주로 나타나는 집단주의는 소속된 집단의 사회적 질서를 중요시하기 때문에 공동운명 또는 상호의존의 관계로 만들어지는 단결을 강조한다(Hofstede, 1980; Kim et al., 1994). 특히 한국은 유교 문화의 영향을 받았기 때문에 사회 구성원들과 조화를 강조하고 집단의 안녕과 질서가 우선시 되어야 한다는 관념을 가지고 있다. 따라서 선수의 스캔들에 대한 사후 대응 전략은 문화권에 따라 상이하게 적용될 수 있을 것이다. 실제 2004년 미국의 수영선수인 마이클 펠프스(Michael Phelps)는 마리화나를 피우는 사진이 영국의 타블로이드판에 공개되어 비난을 받은 적이 있다. 이러한 스캔들이 발생 되었을 때 마이클 펠프스는 부인(denial)하지 않고 신속하게 사죄를 했으며, 해당 조직은 부정적 인식을 완화하려는 노력을 펼친 것이 이미지 회복에 효과적이었다고 했다(Walsh et al., 2011). 이는 당사자가 사과는 커녕 책임을 인정하지 않고 부인하는 자세(denial posture)를 보이면 대중들은 부정적일 반응을 나타낼 수도 있음을 시사한다. 또한, 스캔들은 스포츠의 공정성을 훼손할 뿐 아니라 소속구단과 프로 연맹 전체에 타격을 주기도 한다(Hill, 2010). 선수와 관련된 조직의 대외이미지가 손상될 수 있다는 것이다. 따라서 소속 팀은 스캔들에 대해 책임질 부분이 있다고 인정을 하고 사과하는 것이 조직의 위기상황을 극복하는 데 도움이 될 수 있다(Coombs, 2014). 즉, 국내에서는 선수의 스캔들에 대해 해당 소속팀과 리그 차원에서도 책임을 통감하며 사과를 하는 것이 좋은 대처방안이 될 수 있다.

\section{3. 스포츠 소비자들이 인식하는 선수의 스캔들에 대한 책임과 사과}

Won과 $\operatorname{Ham}(2010)$ 은 운동선수에게는 더욱 높은 도덕성이 요구되고 그들이 스포츠 가치를 훼손했을 때 해당 선수에 대한 비판이 커진다고 하였다. 즉, 페어플레이나 스포츠맨십을 기대하고 있던 팬들이 비행을 일으킨 선수에게 실망하게 되면, 자숙 및 사과를 요구하거나 정당한 처벌을 기대할 수도 있다. 인간은 사회적 상호작용을 통한 다양한 역할을 경험하고 학습하면서 자아가 형성된다고 한다. 그리고 자아는 개인에게 독특하고 고유한 특성을 가짐과 동시에 사회적 산물이라고 할 수 있다. 이러한 자아관은 소속된 사회가 갖는 문화적 특성으로 달라지며 개인주의와 집단주의로 연결될 수 있다(Triandis, 1989). 이에 동양 문화권과 서양 문화권에서는 소비자들이 서로 다른 자기해석(self-construal)을 하게 된다. 따라서 운동선수의 스캔들이 발생했을 때 소비자들은 서로 다른 자기해석수준으로 인해 책임의 범위 및 사과의 주체를 다르게 인식할 수 있다. 그러나 분명한 것은 운동선수는 스포츠가 지닌 순수한 가치를 실현하는 존재라고 여겨지는 것이다. 일반적으로 운동선수들은 공인으로 여겨지기 때문에 이들의 행위에 대하여 일반 대중들은 엄중한 도덕적 행위를 요구한다(Lee \& Lee, 2001). 따라서 운동선수는 경기와 관련된 페어플레이뿐만 아니라 경기와 관련 없는 사생활에서도 더욱 엄격한 윤리적 기준이 적용될 수 있다. 또한, 동서양을 막론하고 소비자들은 윤리적인 기준으로 선수의 스캔들을 판단할 수 있으므로 스캔들에 대한 비판으로부터 자유로울 수 없다. 결국 스포츠 현장에서 발생하는 스캔들은 종류를 불문하고 스포츠의 가치를 훼손하는 일종의 반사회적 행동(antisocial behavior)인 것이다(Kavussanu \& Boardely, 2009). 본 연구의 결과처럼 한국의 스포츠 소비자들은 그들의 집단주의와 상호의존적 성향의 영향을 받으며 운동선수의 스캔들을 판단한다. 국내의 스포츠 
소비자들은 경기와 관련된 스캔들이 발생하면 미국과 달리 선수의 책임뿐만 아니라 해당 소속팀과 리그까지도 책임소재를 물을 수 있음을 보였다. 이는 동양 문화권에서 선수 스캔들에 대한 사과의 주체 또한, 팀과 리그 차원에서도 이뤄져야 한다는 것을 시사한다. 이러한 책임은 국내의 팀과 리그가 대승적인 관점에서 책임을 통감하고 사과를 해야 하는 반면 서양권인 미국은 스캔들을 일으킨 선수 본인의 책임에 초점을 높이고 소속팀과 리그 차원의 책임 및 사과는 동양권보다 상대적으로 약하게 인식한다. 그리고 국내 스포츠 소비자들은 스캔들에 대해서 리그 차원보다 팀 차원의 책임과 사과의 필요성을 더 높게 인식했다. 이는 스포츠 소비자에게 소속팀은 선수에게 가장 가깝게 연결된 관리 집단이라고 인식하고 있기 때문이라 할 수 있다. 따라서 선수의 부도덕한 행위를 관리하지 못한 책임이 더 높다고 인지할 수 있음을 시사한다. 물론 구단에서는 선수의 스캔들을 예방하는 것이 가장 이상적인 전략이겠지만, 운동선수의 비행은 팀 관리자들이 예측할 수 없으며 통제할 수 없는 영역에서 발생하는 경향이 강하다(Lee \& Kwak, 2016). 이는 국내에서 선수 스캔들이 발생하였을 때 팀을 비롯한 상위 조직의 신속한 대처와 상황을 극복하기 위한 전략적 접근이 매우 중요하다는 것을 시사한다고 할 수 있다. Yang과 $\operatorname{Kang}(2019)$ 은 조직이 위기상황 단계에 직면하면 언론대응을 최소화하고 신속히 사과문을 발표하는 것이 효과적이라고 주장한 바 있다. 즉, 국내의 스포츠 조직은 선수의 스캔들에 대해 그 행위를 분리하는 비난 전가(shift the blame)의 태도를 보이는 것은 좋지 않을 것이다. 결국, 내외부적으로 선수의 부도덕한 행위가 일어나게 될 때 실망한 팬들의 마음을 회복시키기 위해 관계자 및 상위 조직에서 책임을 통감하고 신속히 사과하며 이에 따른 후속 조치가 필요할 것이다.

\section{결론 및 제언}

본 연구는 운동선수의 스캔들이 발생했을 때 스포츠 소비자들이 그들의 자기해석수준과 문화권에 따라 인지하는 책임의 범위와 사과의 주체를 교차문화(cross-cultural)연구를 통해 실증적으로 규명하였다. 본 연구를 통해 도출된 결과 및 시사점을 제시하고자 한다.

첫째, 집단주의가 강한 동양 문화권 국가인 한국의 스포츠 소비자들과 개인주의가 강한 서양 문화권 국가인 미국의 스포츠 소비자들은 운동선수의 스캔들에 대해 서로 다른 반응을 보인다. 구체적으로 한국은 미국보다 선수 책임을 상대적으로 낮게 인식했지만, 팀, 리그 차원의 책임과 사과를 미국보다 상대적으로 높게 인식했다. 둘째, 운동선수의 스캔들에 대한 책임은 양쪽 국가 모두 선수, 팀, 리그 순으로 높게 인식했다. 셋째, 운동선수의 스캔들에 대한 사과의 필요성은 양쪽 국가 모두 소속 팀이 리그보다 높게 인식했다. 이상과 같은 연구 결과를 토대로 도출된 시사점은 다음과 같다. 먼저 본 연구는 선수가 스캔들을 일으켰을 때의 책임의 범위와 사과의 주체를 서로 다른 문화적 배경을 통해 구분하고 실증적으로 확인했다는 관점에서 의의가 있다. 국내 스포츠계에서도 선수의 승부 조작, 음주운전, 폭력 등의 스캔들은 과거로부터 끊임없이 발생 되고 있다. 이러한 부정적 상황은 그에 대한 책임과 사과 그리고 징계의 후속 절차가 수반된다. 이를 받아들이고 인식하는 팬들의 상이한 반응을 문화적 배경에 따른 자기해석수준의 차이에 따라 연구함으로써 운동선수 스캔들에 대한 이론적 영역을 확장했다고 볼 수 있다. 또 다른 시사점으로는 동양과 서양은 자기해석수준이 다르므로 선수의 스캔들에 대한 책임이
서구권인 미국에서는 소속팀과 리그의 잘못보다는 해당 선수의 책임이라고 높게 인식한다. 하지만 한국은 선수 잘못뿐만 아니라 소속팀과 리그 차원에서도 책임을 지고 사과해야 한다고 인식한다는 점이다. 그리고 리그보다 소속 팀 차원의 사과를 높게 인식했다. 이는 팀이 스캔들을 일으킨 선수를 보유하고 있으며, 직접관리를 해야 하는 가장 가까운 조직이기 때문으로 이해될 수 있다.

마지막으로 연구의 제한점은 다음과 같다. 첫째, 본 연구에서는 자기해석수준과 관련하여 서양권 국가의 미국과 동양권의 한국에 집중하여 연구를 진행하였다. 미국은 서양 문화권을 대표하는 국가이지만, 본 연구에서는 미국과 다른 문화, 경제, 정치 구조로 되어 있는 유럽 국가들을 고려하지 않았다. 그리고 동양 문화권에서는 한국만을 선정한 만큼 타 국가들(중국, 일본 등)의 속성에 본 연구의 결과를 적용하는 것에는 주의할 필요가 있다. 더불어 본 연구에서는 문화 인지학자들의 선행연구들이 지속적으로 검증해 온 동서양의 문화권에 따라 자기해석수준이 달라진다는 이론적 결과를 기본 가정으로 하여 한국과 미국의 자기해석수준을 점검하지 않았다. 하지만, 향후 후속연구가 이러한 사전 점검을 사용하여 진행된다면 본 연구 결과의 타당도를 높이는 데에 기여할 것으로 예상된다. 둘째, 사회심리학자들(Handel et al., 2018; Nisbett, 2004; Varnum et al., 2010)에 따르면 국제화를 통해 혼합 민족화가 되어가는 국제 사회에도 동·서양의 문화적 차이를 비롯하여 국가별 구성원들의 인식체계는 현저한 차이가 있다고 한다. 하지만 초국가적 문화 현상들이 공유되고 있는 상황을 고려해 보았을 때 각각의 국가 내에서도 다양한 요인(연령 혹은 세대)으로 인한 문화적 차이가 존재할 수 있다. 본 연구는 부족한 샘플수와 부적합한 연령대 구성으로 인해 이러한 문화적 차이를 심도 있게 살펴보기에는 제한적이라 할 수 있다. 이를 위해 향후 국가 내 연령대별 문화적 차이에 근거한 비교를 수행하는 연구는 의미 있는 결과를 제시할 것으로 기대된다. 셋째, 언급한 바와 같이 본 연구는 문화 인지학자들의 주장에 근거하여 미국과 한국의 소비자들 간에 명확한 문화적 자기해석수준이 다를 것이라는 가정하에 진행되었다. 그러나 한 문화권 내에서 개인들의 편차를 고려하면 개인들이 모두 동일한 자기해석수준을 가지고 있다고 일반화시키기에는 무리가 있을 수 있다(Triandis et al., 1998). 넷째, 본 연구는 인지된 책임과 사과 변수를 측정하기 위해 자체개발된 각각의 단일문항들을 사용하였다. 상술한 바와 같이 단일문항의 사용은 여러 가지 장점을 제공하기도 하지만, 각각의 단일문항들의 타당성 및 신뢰성을 통계적 방법으로 검증할 수 없다는 제한점이 존재한다. 이를 보완하기 위해 연구자 및 학계 전문가들과 논의를 통해 세심하게 문항들의 내용타당도 검증을 수행하였지만, 여전히 객관적인 검증을 하지 못한 한계가 있다. 이는 향후 후속연구를 통해 접근되어야 할 것이다. 


\section{참고문헌}

Ajzen, I. (1985). From intentions to actions: A theory of planned behavior. Heidelberg: Springer.

An, E. M., \& Lee, B. K. (2011). The Effects of Ad Repetition and Self-Construal on Ad Creativity Perception and Attitude toward the Ad. Advertising Research, (91), 123-152.

Bandura, A., Barbaranelli, C., Caprara, G. V., \& Pastorelli, C. (1996). Mechanisms of moral disengagement in the exercise of moral agency. Journal of Personality and Social Psychology, 71(2), 364-374.

Bang, S. W, \& Kim, K. H. (2013). Conceptualization of Crisis and Development of Its Classification Scheme in Sport Organizations. Korean Journal of Sport Management, 18(4), 85-99.

Bhattacharjee, A., Berman, J. Z., \& Reed, A. (2013). Tip of the hat, wag of the finger: How moral decoupling enables consumers to admire and admonish. Journal of Consumer Research, 39(6), 1167-1184.

Brace, N., Kemp, R., \& Snelgar, R. (2003). SPSS for Psychologists. Hampshire, England.

Brown, K. A., Dickhaus, J., \& Long, M. C. (2012). LeBron James and" The Decision": An empirical examination of image repair in sports. Journal of Sports Media, 7(1), 149-175.

Brown, N. A. (2014). The Convergence of situational crisis communication theory and social media: Empirically testing the effectiveness of sports fan enacted crisis communication. Ph.D. Dissertation. The University of Alabama.

Brown, N., \& Brown, K. A. (2013). When crisis change the game: Establishing a theory of sports crisis communication. In Sports Interest Group of the Association for Education of Journalism and Mass Communication 2013 annual conference, Washington DC, US.

Chien, P. M., Kelly, S. J., \& Weeks, C. S. (2016). Sport scandal and sponsorship decisions: Team identification matters. Journal of Sport Management, 30(5), 490-505.

Coombs, W. T. (2014). Ongoing crisis communication: Planning, managing, and responding. Sage Publications. (4th ed.). Thousand Oaks, CA: Sage.

Cousins, S. D. (1989). Culture and self-perception in Japan and the United States. Journal of Personality and Social Psychology, 56(1), 124-131.

Faul, F., Erdfelder, E., Buchner, A., \& Lang, A.-G. (2009). Statistical power analyses using $\mathrm{G}^{*}$ Power 3.1: Tests for correlation and regression analyses. Behavior Research Methods, 41, 1149-1160.

Faul, F., Erdfelder, E., Lang, A.-G., \& Buchner, A. (2007). G*Power 3: A flexible statistical power analysis program for the social, behavioral, and biomedical sciences. Behavior Research Methods, 39, 175-191.

Hanel, P. H., Maio, G. R., Soares, A. K., Vione, K. C., de Holanda Coelho, G. L., Gouveia, V. V., Patil, A. C., Kamble, S. V., \& Manstead, A. S. R. (2018). Cross-cultural differences and similarities in human value instantiation. Frontiers in Psychology, 9, 1-13.

Hardin, E. E., Leong, F. T., \& Bhagwat, A. A. (2004). Factor structure of the self-construal scale revisited: Implications for the multidimensionality of self-construal. Journal of Cross-Cultural Psychology, 35(3), 327-345.

Hill, D. (2010). A critical mass of corruption: why some football leagues have more match-fixing than others. International Journal of Sports Marketing and Sponsorship.11(3), 38-52.

Hofstede, G. (1980). Culture and organizations. International Studies of Management \& Organization, 10(4), 15-41.

Hofstede, G., \& Bond, M. H. (1988). The confucius connection: From cultural roots to economic growth. Organizational Dynamics, 16(4), 5-21.

Hughes, S., \& Shank, M. (2005). Defining scandal in sports: Media and corporate sponsor perspectives. Sport Marketing Quarterly, 14(4), 207-216

Huh, H. R. (2003). Scandal: Elite and Media in Korea. Nanam.

Isaacson. T. E. (2012). Evaluating the crisis response strategies of a university basketball program: How do reactions differ based on apologies, crisis severity, and team identification? Ph.D. Dissertation. Michigan State University.

Iyer, A., Jetten, J., \& Haslam, S. A. (2012). Sugaring o'er the devil: Moral superiority and group identification help individuals downplay the implications of ingroup rule-breaking. European Journal of Social Psychology, 42(2), 141-149.

Kanagawa, C., Cross, S. E., \& Markus, H. R. (2001). "Who am I?" The cultural psychology of the conceptual self. Personality and Social Psychology Bulletin, 27(1), 90-103.

Kang, J. M. (2007). Seung Hui Cho incident: Categorized temperament and Essentialism in Korean. Inmul, 52-63.

Kavussanu, M., \& Boardley, I. D. (2009). The prosocial and antisocial behavior in sport scale. Journal of Sport and Exercise Psychology, 31(1), 97-117.

Kelly, S. J., Weeks, C. S., \& Chien, P. M. (2018). There goes my hero again: sport scandal frequency and social identity driven response. Journal of Strategic Marketing, 26(1), 56-70.

Kim, C. S. (2007). Analysis of Article : virginia tech shooting. Newspaper \& Broadcasting, 438, 76-81.

Kitayama, S., Duffy, S., Kawamura, T., \& Larsen, J. T. (2003). Perceiving an object and its context in different cultures: A cultural look at new look. Psychological Science, 14(3), 201-206.

Lee, J. S., \& Kwak, D. H. (2016). Consumers' responses to public figures' transgression: Moral reasoning strategies and implications for endorsed brands. Journal of Business Ethics, 137(1), 101-113.

Lee, J. S., Kim, D., Jang, W., \& Jun, S. (2021). The scarlet letter: Impacts of moral emotions and attribution type on athlete stigmatization. European Sport Management Quarterly, 1-19.

Lee, J. S., Kwak, D. H., \& Bagozzi, R. P. (2020). Cultural cognition and endorser scandal: Impact of consumer information 
processing mode on moral judgment in the endorsement context. Journal of Business Research, 132, 906-917.

Lee, J. S., Kwak, D. H., \& Braunstein-Minkove, J. R. (2016). Coping with athlete endorsers' immoral behavior: Roles of athlete identification and moral emotions on moral reasoning strategies. Journal of Sport Management, 30(2), 176-191.

Lee, J. S., Kwak, D. H., \& Moore, D. (2015). Athletes' transgressions and sponsor evaluations: A focus on consumers' moral reasoning strategies. Journal of Sport Management, 29(6), 672-687.

Lee, S., Lee, A. Y., \& Kern, M. C. (2011). Viewing time through the lens of the self: The fit effect of self-construal and temporal distance on task perception. European Journal of Social Psychology, 41(2), 191-200.

Lee, W. S., Shim, J. W., Shim, J. C. (2008). Media Salience and the Dynamic Process of News Frame Changing : Coverage of the Virginia Tech Shootings in Korea and the USA. Korean Journal of Journalism \& Communication Studies, 52(1). 386-412.

Lim, J. E. (2019). Matching effect of temporal distance, self-construal, regulatory focus and temporal consequences. Korean Journal of Consumer and Advertising Psychology, 20(20). 257-277.

Louie, T. A., Kulik, R. L., \& Jacobson, R. (2001). When bad things happen to the endorsers of good products. Marketing Letters, 12(1), 13-23.

Markus, H. R., \& Kitayama, S. (1991). Culture and the self: Implications for cognition, emotion, and motivation. Psychological Review, 98(2), 224-253.

Markus, H. R., Uchida, Y., Omoregie, H., Townsend, S. S., \& Kitayama, S. (2006). Going for the gold: Models of agency in Japanese and American contexts. Psychological Science, 17(2), 103-112.

Nisbett, R. (2004). The geography of thought: How Asians and Westerners think differently... and why. Simon and Schuster. NY: The Free Press.

Nisbett, R. E., \& Masuda, T.(2003). Culture and point of view. Processing of the National Academy of Sciences, 100(19), 1116311170.

Nisbett, R. E., \& Miyamoto, Y. (2005). The influence of culture: Holistic versus analytic perception. Trends in Cognitive sciences, 9(10), 467-473.

Nisbett, R. E., Peng, K., Choi, I., \& Norenzayan, A. (2001). Culture and systems of thought: Holistic versus analytic cognition. Psychological Review, 108(2), 291-310.

Osborne, A., Sherry, E., \& Nicholson, M. (2016). Celebrity, scandal and the male athlete: A sport media analysis. European Sport Management Quarterly, 16(3), 255-273.

Park, H. W., \& Park, J. J. (2011). Sports players' scandals and the crisis communication strategies. Journal of Communication Science, 11(4), 259-295.

Park, J. C., \& Ryu, G. S. (2012). The Influence of Temporal Construal and Self-Construal on Consideration Set Formation. Journal of Counsumer Studies, 23(1), 29-53.
Shen, H., Wan, F., \& Wyer Jr, R. S. (2011). Cross-cultural differences in the refusal to accept a small gift: The differential influence of reciprocity norms on Asians and North Americans. Journal of Personality and Social Psychology, 100(2), 271-281.

Singelis, T. M. (1994). The measurement of independent and interdependent self-construals. Personality and Social Psychology Bulletin, 20(5), 580-591.

Spassova, G., \& Lee, A. Y. (2013). Looking into the future: A match between self-view and temporal distance. Journal of Consumer Research, 40(1), 159-171.

Trail, G., \& James, J. (2001). The motivation scale for sport consumption: Assessment of the scale's psychometric properties. Journal of Sport Behaviour, 24(1), 108-127.

Triandis, H. C. (1989). The self and social behavior in differing cultural contexts. Psychological Review, 96(3), 506-520.

Triandis, Xiao Ping Chen, and Darius K. Chan(1998), "Scenarios for the Measurement of Collectivism and Individualism,". Journal of Cross-Cultiral Psychology, 29(2), 275-289.

Van Baaren, R. B., Maddux, W. W., Chartrand, T. L., De Bouter, C., \& Van Knippenberg, A. (2003). It takes two to mimic: Behavioral consequences of self-construals. Journal of Personality and Social Psychology, 84(5), 1093-1102.

Varnum, M. E., Grossmann, I., Kitayama, S., \& Nisbett, R. E. (2010). The origin of cultural differences in cognition: The social orientation hypothesis. Current Directions in Psychological Science, 19(1), 9-13.

Waterman, A. S. (1984). The psychology of individualism. Greenwood.

Won, Y. S., \& Ham, E. J. (2008). Media sport plus. Daekyung books.

Yang, S. H., \& Kang, J. H. (2019). Crisis Communication Strategies of Professional Sport Clubs : A Case Study of Baseball Umpire Money Transaction Scandal by Big Data Analytics Tools. Korean Society For Sport Management, 24(2), 15-31.

Yi, H. K., \& Lee, H. J. (2001). Why should athletes look like ethical?. The Korean Society for the Philosophy of Sport, Dance \& Martial Arts. 9(2). 75-84.

Zaichkowsky, J. L. (1985). Measuring the involvement construct. Journal of Consumer Research, 12(3). 341-352.

Zhang, Y., \& Gelb, B. D. (1996). Matching advertising appeals to culture: The influence of products' use conditions. Journal of Advertising, 25(3), 29-46. 


\title{
자기해석수준에 따른 운동선수 스캔들에 대한 소비자들의 반응: 교차문화(cross-cultural)적 접근
}

\author{
남궁진 ${ }^{1}$, 이준성 ${ }^{2}$ \\ 1 연세대학교 박사과정 \\ 2 연세대학교 교수
}

[목적] 연구는 운동선수의 스캔들에 대한 스포츠 소비자들의 반응이 그들의 문화적 배경에 따른 자기해석(self-construal)수 준의 차이에 영향을 받는다는 것을 교차문화(cross-cultural)연구를 통해 실증적으로 규명하는 데 목적이 있다.

[방법] 국가별 비교 연구(a cross-national comparative study)를 위해 한국과 미국에서 실험 참가자(한국=75, 미국= 76)를 모집하였다. 이후 참가자들에게 사전연구를 통해 제작된 가상의 스포츠 스캔들 시나리오를 제시하여 반응을 살펴 보았다. 연구 가설을 검증하기 위해 SPSS ver.26을 사용하여 다변량공분산분석(Multivariate Analysis of Covariance: MANCOVA)과 기술통계 분석(Descriptive Statistical Analysis)을 실시하였다.

[결과] 소비자들은 그들이 속한 문화권에 따라 스캔들에 대한 책임의 범위와 사과의 주체를 다르게 인식했다. 한국 소비 자들은 스캔들에 대해 소속팀과 리그 차원에서도 책임이 있고 사과를 해야 한다고 인식했으며, 미국 소비자들은 스캔들 의 주체인 선수의 책임이 높다고 인식했다.

[결론] 본 연구의 결과는 스포츠 스캔들에 관한 판단과 반응 방식이 상호의존적인 자기 개념이 강한 한국과 독립적인 성 향을 지닌 미국의 소비자들 간에 차이가 있음을 나타낸다. 본 연구는 국제화가 되어가는 스포츠 산업의 관점에서 선수의 스캔들로 인해 유발되는 팬들의 반응이 문화권에 따라 상이하다는 점을 실증적으로 밝혀내어 중요한 시사점을 제공할 수 있을 것이다.

주요어

자기해석, 개인주의, 집단주의, 선수 스캔들, 문화 차이 